\section{(2) OPEN ACCESS}

\title{
The Severe Respiratory Insufficiency Application (SRI App): a pilot randomised controlled trial
}

\author{
Daniel Sebastian Majorski, ${ }^{1}$ Sarah Bettina Schwarz 다, ${ }^{1}$ Friederike Sophie Magnet, ${ }^{1}$ \\ Rebar Ahmad, ${ }^{2}$ Tim Mathes, ${ }^{3}$ Wolfram Windisch ${ }^{1,4}$
}

Lung Clinic, Kliniken der Stadt Köln gGmbH, Köln, Germany ${ }^{2}$ Informatics, Hochschule Niederrhein, Krefeld, Germany ${ }^{3}$ Institute for Research in Operative Medicine, University Witten/Herdecke, Köln, Germany ${ }^{4}$ Faculty of Health, Universität Witten/Herdecke, Witten, Germany

Correspondence to Professor Wolfram Windisch, Lung Clinic, Kliniken der Stadt Koln gGmbH, Koln 51103, Nordrhein-Westfalen, Germany; windischw@kliniken-koeln.de

This trial was presented at the ERS International congress 2020 as a poster.

Received 6 October 2020 Revised 8 December 2020 Accepted 31 January 2021 Published Online First 2 March 2021

\section{ABSTRACT}

An application (app) for the Severe Respiratory Insufficiency Questionnaire (SRI) has been designed and developed for mobile devices. In a randomised controlled trial comprising 60 patients with chronic respiratory failure, the app was compared with the classic paper SRI. Thereby, it was shown that the SRI app is a practical tool that is well accepted. Missing values can be completely avoided by using the SRI app. Finally, reliability, convergent and discriminant validities were established. Accordingly, for the individual SRI subscales, Cronbach's alpha ranged between 0.56 and 0.81 (app) and between 0.54 and 0.83 (paper), respectively. The multilingual SRI app is accessible free of charge for non-profit research purposes.

\section{INTRODUCTION}

The Severe Respiratory Insufficiency Questionnaire (SRI) is a specific, well-validated measure of health-related quality of life (HRQL). ${ }^{1}$ It has been specifically designed to evaluate HRQL in patients receiving long-term non-invasive ventilation (NIV) therapy and/or long-term oxygen therapy (LTOT). ${ }^{2}$ The questionnaire has originally been developed in German and since been professionally translated into an additional 16 languages. A minimal clinically important difference of approximately five points for the SRI was recently established. ${ }^{3}$ Currently, the SRI is the tool most frequently used for assessing HRQL in patients with chronic respiratory failure, ${ }^{4}$ and is also commonly applied in large trials investigating the impact of long-term NIV on HRQL. ${ }^{5-8}$ The present trial was aimed at designing, developing and testing the SRI app. Thereby, it was hypothesised that the SRI app is applicable and has acceptable psychometric properties.

\section{METHOD}

This trial was conducted as a pilot trial at the Lung Clinic, Cologne Merheim Hospital, Witten/ Herdecke University, Germany. The SRI was used to assess HRQL in patients with chronic respiratory failure who were undergoing LTOT and/or long-term NIV therapy. Patients were randomised to complete either the classic paper version of the questionnaire or the electronic version of the SRI using a tablet computer (Apple iPad mini, Model A2124). An SRI app was specifically designed and developed by a professional app developer (Rebar Ahmad). The average time taken to complete each version of the SRI (paper vs electronic) was measured. Finally, those patients who were randomised to the app group carried out an evaluation of the app using a real-world user-centric statistical method known as the User Experience Questionnaire. ${ }^{9}$ The level of agreement between the electronic and the paper version of the SRI was assessed by comparing the mean difference between the respective scores and their 95\% CIs. A multivariate analysis of variance adjusted for age, gender, body mass index, type of respiratory disease, and duration of NIV, was used. To determine and compare internal consistency, Cronbach's alpha with 95\% CIs for each group was calculated. In addition, the correlation matrix was calculated to assess convergent (correlation of items within the same SRI subscale) and discriminant validity (correlation of items from different SRI subscales). Missing data were imputed using multiple imputation at the item level. Statistical analysis was performed using SPSS V.25 (IBM SPSS Statistics for Windows, 2017).

\section{RESULTS}

Overall, 60 patients were randomised: 30 patients (22 with COPD, 3 with neuromuscular disorders, 2 with idiopathic kyphoscoliosis, 2 with interstitial lung disease and 1 with post acute respiratory distress syndrome) filled in the classic paper version of the SRI, while 30 patients ( 24 with COPD, 4 with obesity hypoventilation syndrome, 1 with interstitial lung disease and 1 with post-tuberculosis) filled in the SRI using the app. Patient characteristics are provided in table 1 . Overall, the mean duration of long-term NIV $(\mathrm{N}=37)$ versus LTOT $(\mathrm{N}=49)$ was $33.8 \pm 50.4$ and $31.9 \pm 43$ months, respectively.

Accordingly, the adjusted mean difference $(\Delta)$ in the SRI Summary Score was -0.69 (95\% CI: -7.70 to $6.36 ; \mathrm{p}=0.85)$, whereby a score of 0 to 100 represents the worst to best HRQL. No relevant differences were observed on any of the subscales, with the exception of 'respiratory complaints' $(\Delta-9.90$ (95\% CI: -19.45 to $0.43 ; \mathrm{p}=0.04)$. The interitem correlation matrix of all variables confirmed convergent validity on a subscale level, as well as discriminant validity. Accordingly, Eleven out of thirty patients in the classic paper SRI group demonstrated at least one missing value by either skipping single questions or incorrectly marking more than one answer per item (which was ultimately counted as a missing value). This led to a total of 43 missing items in the paper SRI group. In contrast, no missing items were found in the SRI app group $(p=<0.001)$. Cronbach's alpha was $\geq 0.54$ for all subscales, $\geq 0.7$ for four subscales and 0.9 for the Summary Score (table 2). The average time to completion was $12: 30 \pm 6: 22 \mathrm{~min}$ :s for the paper SRI group and 11:28 $\pm 6: 20 \mathrm{~min}: \mathrm{s}$ for the SRI 
Table 1 Demographic data, lung function parameters and daytime blood gases

\begin{tabular}{|c|c|c|}
\hline Characteristics & SRI app $(\mathrm{N}=30)$ & SRI paper $(\mathrm{N}=30)$ \\
\hline Age (years) & $66.9( \pm 10.3)$ & $69.4( \pm 9.4)$ \\
\hline Female sex(\%) & 40 & 40 \\
\hline $\mathrm{FEV}_{1}$ after bronchodilation (\%pred) & $37.4( \pm 19.8)$ & $37.2( \pm 14.3)$ \\
\hline FVC (\%pred) & $54.5( \pm 23.5)$ & $58.1( \pm 19.4)$ \\
\hline $\mathrm{FEV}_{1} / \mathrm{FVC}$ ratio (\%pred) & $52.6( \pm 19.6)$ & $49.5( \pm 16.2)$ \\
\hline TLC (\%pred) & $99.9( \pm 23.1)$ & $102.6( \pm 31.5)$ \\
\hline RV (\%pred) & $161.1( \pm 60.8)$ & $179.3( \pm 78.2)$ \\
\hline BMI $\left(\mathrm{kg} / \mathrm{m}^{2}\right)$ & $27( \pm 8.3)$ & $28.3( \pm 7.9)$ \\
\hline $\mathrm{pH}$ & $7.43( \pm 0.04)$ & $7.42( \pm 0.04)$ \\
\hline $\mathrm{PaO}_{2}(\mathrm{~mm} \mathrm{Hg})$ & $68.6( \pm 16)$ & $61( \pm 10.7)$ \\
\hline $\mathrm{PaCO}_{2}(\mathrm{~mm} \mathrm{Hg})$ & $45( \pm 7.1)$ & $47.7( \pm 6.1)$ \\
\hline $\mathrm{HCO}_{3}^{-}(\mathrm{mmol} / \mathrm{L})$ & $28.7(3.4)$ & $28.9( \pm 3.2)$ \\
\hline LTOT (in \%) & 66.7 & 70.0 \\
\hline NIV (in \%) & 56.7 & 63.3 \\
\hline
\end{tabular}

ARDS, Acute respiratory distress syndrome; BMI, body mass index; COPD, Chronic obstructive Pulmonary disease; $\mathrm{FEV}_{1}$, forced expiratory volume in one second; FVC, forced vital capacity; $\mathrm{HCO}_{3}{ }^{-}$, arterial standard hydrogen carbonate; LTOT, long-term oxygen therapy; NIV, noninvasive ventilation; $\mathrm{PaCO}_{2}$, arterial partial pressure of carbon dioxide; $\mathrm{PaO}_{2}$, arterial partial pressure of oxygen; RV, residual volume; SRI, Severe Respiratory Insufficiency Questionnaire; TLC, total lung capacity.

app group $(p=0.22)$. When compared with the existing values from a benchmark dataset, the SRI was scored as good or excellent in all categories (figure 1).

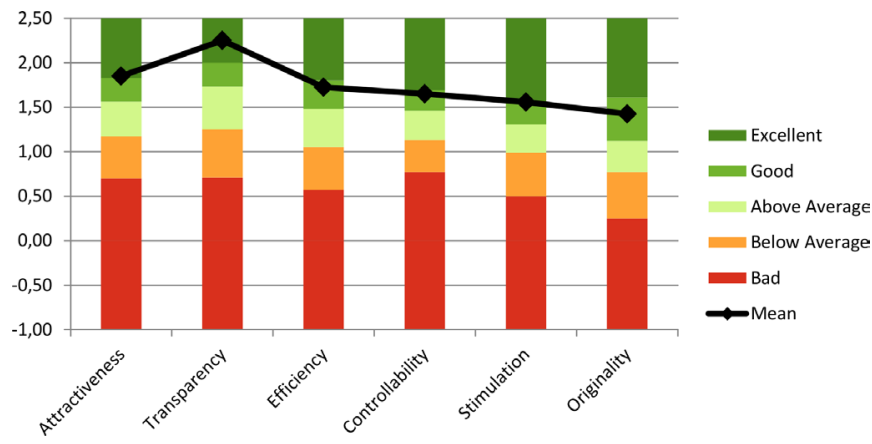

Figure 1 The results of the User Experience Questionnaire categories for the Severe Respiratory Insufficiency Questionnaire (SRI) Application (app) in comparison to benchmark data. The black line represents the mean values of results generated by the 30 study patients who filled in the SRI on the app. Coloured columns represent benchmark testing of over 18483 datasets, ${ }^{10}$ with the following definitions: Excellent: within the range of the top $10 \%$ of results; Good: $10 \%$ of the results were better, $75 \%$ of the results were worse.

\section{DISCUSSION}

The present study clinically tested and assessed the psychometric properties of an SRI app that was designed and developed for mobile electronic devices. The main results are as follows: First, the SRI app is a practical tool that is well accepted by patients with severe chronic respiratory failure. Second, in contrast to the classic paper SRI, the usage of the SRI app completely prevents the occurrence of missing values. Third, calculation of Cronbach's alpha suggested

Table 2 Mean interitem correlation for items within a subscale and between items outside of the investigated subscale.

\begin{tabular}{|c|c|c|c|c|c|}
\hline Scale & $\begin{array}{l}\text { Mean } r \\
\text { (within subscale) }\end{array}$ & $\begin{array}{l}\text { Mean } r \\
\text { (outside subscale) }\end{array}$ & Adjusted mean difference $95 \% \mathrm{Cl}$ & $P$ value & Cronbach's alpha \\
\hline $\begin{array}{l}\text { App: } \\
\text { SRI-RC }\end{array}$ & 0.319 & 0.19 & $-9.9(-19.5$ to 0.43$)$ & 0.04 & 0.79 \\
\hline $\begin{array}{l}\text { Paper: } \\
\text { SRI-RC }\end{array}$ & 0.215 & 0.152 & & & 0.69 \\
\hline $\begin{array}{l}\text { App: } \\
\text { SRI-PF }\end{array}$ & 0.175 & 0.15 & $4.67(-6.6$ to 15.9$)$ & 0.41 & 0.56 \\
\hline $\begin{array}{l}\text { Paper: } \\
\text { SRI-PF }\end{array}$ & 0.438 & 0.154 & & & 0.83 \\
\hline $\begin{array}{l}\text { App: } \\
\text { SRI-AS }\end{array}$ & 0.191 & 0.181 & $-6.8(-15.8$ to 2.2$)$ & 0.14 & 0.63 \\
\hline $\begin{array}{l}\text { Paper: } \\
\text { SRI-AS }\end{array}$ & 0.144 & 0.059 & & & 0.54 \\
\hline $\begin{array}{l}\text { App: } \\
\text { SRI-SR }\end{array}$ & 0.274 & 0.152 & $-1.4(-10.3$ to 7.6$)$ & 0.76 & 0.7 \\
\hline $\begin{array}{l}\text { Paper: } \\
\text { SRI-SR }\end{array}$ & 0.261 & 0.134 & & & 0.63 \\
\hline $\begin{array}{l}\text { App: } \\
\text { SRI-AX }\end{array}$ & 0.47 & 0.194 & $4(-8.5$ to 16.6$)$ & 0.53 & 0.81 \\
\hline $\begin{array}{l}\text { Paper: } \\
\text { SRI-AX }\end{array}$ & 0.263 & 0.128 & & & 0.64 \\
\hline $\begin{array}{l}\text { App: } \\
\text { SRI-WB }\end{array}$ & 0.284 & 0.205 & $-0.5(-9.9$ to 8.9$)$ & 0.92 & 0.78 \\
\hline $\begin{array}{l}\text { Paper: } \\
\text { SRI-WB }\end{array}$ & 0.204 & 0.15 & & & 0.7 \\
\hline $\begin{array}{l}\text { App: } \\
\text { SRI-SF }\end{array}$ & 0.233 & 0.201 & $5.1(-4.4$ to 14.6$)$ & 0.29 & 0.7 \\
\hline $\begin{array}{l}\text { Paper: } \\
\text { SRI-SF }\end{array}$ & 0.185 & 0.143 & & & 0.63 \\
\hline
\end{tabular}


the reliability of the app, while convergent and discriminant validity could also be suggested, even though further assessment is necessary, since non-significant $\mathrm{p}$ values in the correlation matrix could be due to lacking sample size calculation resulting in a lack of the statistical power. Here, differences in subscale scores between the paper and electronic SRI might exist due to less missing items when using the electronic version.

The time taken to fill in the SRI was comparable in both the classic paper SRI and SRI app groups. Thus, patients with severe disabilities and chronic respiratory failure-such as those included in the present study-are able to use modern electronic devices if the device is as intuitively designed as the SRI app. From a technical perspective, the SRI app was rated as good or excellent by patients when compared with average benchmark product testing. ${ }^{10}$ Moreover, according to the conceptual framework of the SRI app, only one answer can be given per item. In addition, patients are also reminded to fill in all missing items prior to finalising the questionnaire; therefore, this clearly explains how missing values are completely avoided by using the app.

Based on these positive findings, researchers are encouraged to use the multilingual SRI app, which can be downloaded free of charge from either the App store or the homepage of the German Airway League (Deutsche Atemwegsliga e.V.): https:// www.atemwegsliga.de/en-sri.html.

Contributors DSM: planning and execution of the trial, statistical analysis and drafting the manuscript. SBS: planning and execution of trial, revising the manuscript. FSM: planning and execution of trial, revising the manuscript. TM: statistical analysis and revising the manuscript. RA: development of the application. WW: planning of the trial, drafting and revising the manuscript.

Funding A grant was provided by the "German Airway League e.V." (Deutsche Atemwegsliga e.V.) for development of the Severe Respiratory Insufficiency Questionnaire Application.

Disclaimer The authors state that neither the study design, results, interpretation of the findings, nor any other subject discussed in the submitted manuscript was dependent on financial support.

Competing interests SBS: received travel grants from companies dealing with mechanical ventilation products. FSM: received speaking fees from companies dealing with mechanical ventilation products. WW received speaking fees from companies dealing with mechanical ventilation products. The Cologne study group
(DSM, JCC, SBS, FSM and WW) received open research grants from Weinmann/ Germany, Vivisol/Germany, Heinen und Löwenstein/Germany, VitalAire/Germany and Phillips Respironics/USA.

Patient consent for publication Not required.

Provenance and peer review Not commissioned; externally peer reviewed.

Open access This is an open access article distributed in accordance with the Creative Commons Attribution Non Commercial (CC BY-NC 4.0) license, which permits others to distribute, remix, adapt, build upon this work non-commercially, and license their derivative works on different terms, provided the original work is properly cited, appropriate credit is given, any changes made indicated, and the use is non-commercial. See: http://creativecommons.org/licenses/by-nc/4.0/.

\section{ORCID iD}

Sarah Bettina Schwarz http://orcid.org/0000-0001-8989-0211

\section{REFERENCES}

1 Windisch W, Freidel K, Schucher B, et al. The severe respiratory insufficiency (Sri) questionnaire: a specific measure of health-related quality of life in patients receiving home mechanical ventilation. J Clin Epidemiol 2003;56:752-9.

2 Walterspacher $S$, July J, Kohlhäufl $M$, et al. The severe respiratory insufficiency questionnaire for subjects with COPD with long-term oxygen therapy. Respir Care 2016:61:1186-91.

3 Raveling T, Kort J, Bladder G, et al. The minimal clinically important difference of the severe respiratory insufficiency questionnaire in severe COPD. Eur Respir J. In Press 2020;56. doi:10.1183/13993003.01334-2020. [Epub ahead of print: 17 Dec 2020].

4 Struik FM, Kerstjens HAM, Bladder G, et al. The severe respiratory insufficiency questionnaire scored best in the assessment of health-related quality of life in chronic obstructive pulmonary disease. J Clin Epidemiol 2013;66:1166-74.

5 Struik FM, Sprooten RTM, Kerstjens HAM, et al. Nocturnal non-invasive ventilation in COPD patients with prolonged hypercapnia after ventilatory support for acute respiratory failure: a randomised, controlled, parallel-group study. Thorax 2014;69:826-34

6 Köhnlein T, Windisch W, Köhler D, et al. Non-Invasive positive pressure ventilation for the treatment of severe stable chronic obstructive pulmonary disease: a prospective, multicentre, randomised, controlled clinical trial. Lancet Respir Med 2014;2:698-705.

7 Murphy PB, Rehal S, Arbane G, et al. Effect of home noninvasive ventilation with oxygen therapy vs oxygen therapy alone on hospital readmission or death after an acute COPD exacerbation: a randomized clinical trial. JAMA 2017;317:2177-86.

8 Duiverman ML, Vonk JM, Bladder G, et al. Home initiation of chronic non-invasive ventilation in COPD patients with chronic hypercapnic respiratory failure: a randomised controlled trial. Thorax 2020;75:244-52.

9 Laugwitz BH, Schrepp M. Construction and evaluation of a user experience questionnaire. USAB 2008:63-76. doi:10.1007/978-3-540-89350-9_6

10 Schrepp M, Hinderks A, Thomaschewski Jörg. Construction of a benchmark for the user experience questionnaire (UEQ). IJIMAI 2017;4:40-4. 